\title{
COMPARISON OF ANESTHETIC PROPERTIES OF KETOFOL (KETAMINE WITH PROPOFOL) AND PROPOFOL IN MINOR SURGICAL PROCEDURES
}

\author{
Karki $S B^{1 *}$, Rajbanshi $L K^{2}$, Ariyal $B^{2}$, Khanal $K^{1}$
}

\section{Affiliation}

1. Consultant Anaesthesiologist, Department of Anaesthesia and Intensive Care, Birat Medical College \& Teaching Hospital

2. Lecturer, Department of Anaesthesiology and critical care. Birat Medical College and Teaching Hospital

\section{ARTICLE INFO}

\section{Article History}

Received : 22 October, 2017

Accepted : 05 November, 2017

Published : 31 December, 2017

(c) Authors retain copyright and grant the journal right of first publication with the work simultaneously licensed under Creative Commons Attribution License CC - BY 4.0 that allows others to share the work with an acknowledgment of the work's authorship and initial publication in this journal.

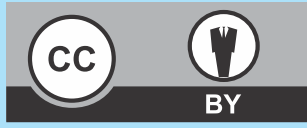

ORA 45

DOI: http://dx.doi.org/10.3126/bjhs.v2i3.18945

\author{
* Corresponding Author \\ Dr. Shambhu Bahadur Karki \\ Consultant Anaesthesiologist \\ Department of Anaesthesia and Intensive Care \\ Birat Medical College \& Teaching Hospital \\ Email:karkisb@yahoo.com
}

\section{Citation}

Karki SB, Rajbanshi LK, Ariyal B, Khanal K. Comparison of Anesthetic Properties of Ketofol (ketamine With Propofol) and Propofol in Minor Surgical Procedures. BJHS 2017;2(3)4 :287-291

\section{ABSTRACT}

\section{Introduction}

Outpatient anesthesia for the minor day care surgical procedures requires a safe anesthesia and anesthetic agents. For this purpose two study solutions propofol with ketamine (ketofol) and propofol were compared. The comparison of the both agents were assessed, evaluated and discussed in this study.

\section{Methodology}

This is prospective study of 100 adult patients of both sex aged between $18-60$ years with ASA physical status class I and II who were operated in the Birat Medical College teaching hospital. This study was started after approval from the ethical committee of the hospital and after written and informed consent from all participants.

All patients were randomly divided into two groups. Group A $(n=50)$ received ketamine with propofol and Group B $(n=50)$ propofol after intravenous sedation with $2 \mathrm{mg}$ of midazolam and $1 \mathrm{mg}$ of butorphanol. The main aim of this study was comparison of onset of sedation, respiratory and cardiac adverse events, level of sedation using Ramsey sedation scale, requirement of sedatives, recovery time, average cost of the sedatives and postoperative complications between the two groups. All collected data are analyzed using MS Excel office 2007 and for the data analysis IBM SPSS software was used.

\section{Results}

In the both groups patients were comfortable with the either anesthetic agents. Onset of anesthesia was faster in Group A. Intraoperative sedation was measured using Ramsay sedation scale and was comparable. Recovery from sedation was assessed with AVPU scale and patient was shifted to postoperative room after the verbal response. Postoperative complications seen were nausea vomiting, severe pain, ketamine induced psychotomimetic effects and all of these were treated well and discharged on the same day from the hospital.

\section{Conclusion}

The combination of ketamine and propofol for the sedation in minor surgical procedures has more advantages than the propofol alone. The combination is cost effective, has better sedation and hemodynamic stability, quick recovery and fewer side effects in the post operative room.

\section{KEYWORDS}

Anesthesia; ketofol; propofol; surgery 


\section{INTRODUCTION}

Minor surgical procedures are outpatient daycare procedures in which patients are admitted, surgical interventions are performed and discharged at the same day. Such outpatient anesthesia demands a safe anesthesia method with the short acting intravenous anesthetic medications, which are able to provide rapid anesthesia depth and hemodynamic stability, rapid metabolism and minimum adverse effects in the recovery period. ${ }^{1 / 2,3}$

Propofol is a short acting anesthetic agent which is used widely for the induction of anesthesia and for the sedation in minor surgical procedures. It is a non opioid, non barbiturate sedo-hypnotic agent with rapid onset and short duration of action. ${ }^{1}$ It produces good sedation and also has antiemetic effect. $^{2}$ Its adverse effects are dose related respiratory and cardiovascular depression, bradycardia and pain during injection. ${ }^{3 \prime 4}$ Propofol is known to produce amnesia with sedative and hypnotic effects but it don't have analgesic property so combination of analgesic molecule is required with propofol for the sedation in surgical procedures. ${ }^{3}$

Ketamine is a phencyclidine derivative which blocks the NMDA receptors and provides dissociative anesthesia, profound analgesia and amnesia. ${ }^{5}$ Ketamine increases heart rate, cardiac output and blood pressure and it has little or no cardiovascular and respiratory depression. It's wide spread use as a sole anesthetic agent for procedural sedation in adults is limited because of its psychotomimetic effects such as vomiting and laryngospasm. The incidence of emergence hallucination effects can be reduced by coadministration of benzodiazepine, barbiturates or propofol. ${ }^{5}$ Ketamine has similar effects as propofol at sedoanalgesic doses and even safer than propofol. ${ }^{3}$

Ketamine and propofol has been used in separate syringes in the same patient successfully in variety of procedures including sedation of spinal anesthesia, minor opthalmological procedures, gynecological and surgical procedures in children and adults. ${ }^{3}$ The main advantage of this combination is the opposing effect in the hemodynamic and respiratory effects of each drug. ${ }^{4{ }^{\prime} 6}$ In a prospective study carried by Friedberg et al in 1264 patients undergoing anesthesia for the surgical procedures with Ketofol (ketamine with propofol), concluded that this combination is safe and effective. ${ }^{3}$ The combination of ketamine with propofol has been shown to reduce the dose of either molecule required for the sedation and analgesia. The reduced doses of this combination provides safe, cost effective and less toxic anesthestic agent than the either drug alone. ${ }^{3}$

The main objective of this study is to compare sedoanalgesia effects of both anesthetic drugs using Ramsay Sedation Score, intraoperative complications with hemodynamic and respiratory changes, requirement of amount of anesthetic solutions, recovery times, cost of the either solutions and postoperative complications in minor surgical procedures.

\section{METHODOLOGY}

This is a prospective study conducted in the Birat Medical College teaching hospital, Biratnagar, Nepal after obtaining approval from the ethical committee of the hospital and after written informed consent from all participants from February 2017 to April 2017. Total 100 patients between 1860 years old with the ASA physical status class I and II were included in the study.

\section{Inclusion criteria:}

1. Age between $18-60$ years

2. Patients with ASA physical status class I and II

3. Minor surgical procedures lasting for less than $30 \mathrm{~min}$ Exclusion Criteria:

1. Patients having allergy to the study solutions

2. Patients with co morbid conditions like cardiovascular diseases, acute respiratory tract infections, acute and chronic hepatic diseases, renal diseases, CNS diseases, psychiatric diseases and the patients with alcohol and drug addiction

3. Pregnant women

4. Patients with ASA physical status class III and IV

5. Surgical procedures lasting more than $30 \mathrm{~min}$

6. Patients who refused to give consent for the study

A routine preoperative fasting of 8 hours was mandatory for all patients. Patients were taken to operating room after pre anesthesia evaluation and preparation. Intravenous line was opened in operating room with $20 \mathrm{G}$ intravenous cannula and RL solution was regularly infused. $4 \mathrm{~L} / \mathrm{min}$ of oxygen was delivered to all patients via face mask during surgery and recovery period. Parameters monitored in the operating room were ECG, NIBP, pulse oxymetry, respiration and sedation score were recorded as follows:

- before induction

- afterincision

- Every 5 min during surgery

- $\quad$ at the end of the procedure

Table1. RAMSAY SEDATION SCALE.

Three awake levels and three asleep levels

1. AWAKE Patient anxious, agitated or restless or both

2. Patient cooperative, oriented and tranquil

3. Patient respond to commands

4. ASLEEP A brisk response to a light glabellar tap or loud auditory stimulus

5. A sluggish response to light glabellar tap or loud auditory stimulus

6. Asleep, no response to light glabellar tap or loud auditory stimulus

All patients were induced with $1 \mathrm{mg}$ of inj butorphanol and 2 mg of Inj midazolam intravenously. The study solution of Group A was prepared with $50 \mathrm{mg}(1 \mathrm{ml})$ of Ketamine, $50 \mathrm{mg}$ $(5 \mathrm{ml})$ of Propofol and $4 \mathrm{ml}$ of Normal Saline (NS) in a $10 \mathrm{ml}$ syringe. The ratio of 1:1 was designed for ketofol group.

Group A patients received $50 \mathrm{mg}(5 \mathrm{ml})$ Ketofol $(25 \mathrm{mg}$ 
ketamine and $25 \mathrm{mg}$ propofol) and Group B received $50 \mathrm{mg}$ $(5 \mathrm{ml})$ of propofol. The top-ups of the anesthetic solution were given up to the abolishment of eye lid reflex. The level of intraoperative sedation was assessed by Ramsey Sedation Scale (RSS). Intraoperative sedation was maintained up to the desired level (RSS 4, 5) by supplementation of the study solution. All the monitored parameters were recorded along with the requirement of the anesthetic solution and intraoperative complications. For the analysis patients were randomly divided into the two groups according to the order of admission in the pre operative preparation room.

$\begin{array}{lc}\text { Table 2. Verbal Rating Scale. } & \\ \text { Pain intensity } & \text { Score } \\ \text { No pain } & 0 \\ \text { Slight pain } & 1 \\ \text { Moderate pain } & 2 \\ \text { Severe pain } & 3 \\ \text { Unbearable pain } & 4\end{array}$

The intermittent top ups was administered to the either group according to the autonomic (pulling extremities, eye opening, crying) and hemodynamic (tachycardia, hypertension) responses. The sedation level was evaluated with the help of Ramsey Sedation Scale (RSS) and was maintained between 4-5 score. All vital parameters were recorded before induction of anesthesia, just after incision and every 5 min during the procedure. The induction time, surgical and recovery times were recorded and analyzed using mean with SD and listed in Table 5. Patients were transferred to postoperative room when they were able to open their eye, protrude the tongue and obey the verbal command according to the AVPU recovery scale. All parameters were closely monitored in postoperative room along with any adverse events and requirement of additional drugs. Inj diclofenac sodium $75 \mathrm{mg}$ IM prescribed for the management of postoperative pain and Inj metoclopramide $10 \mathrm{mg}$ IV for the postoperative nausea vomiting (PONV).

All recorded intraoperative and post operative data were collected and analyzed using SPSS. Results are expressed as mean \pm SD percentage and frequency.

\section{RESULTS}

The study was conducted during 3 months period in which 50 patients had procedural sedation with ketofol (propofol and ketamine) and 50 patients with propofol. Patient demographics are listed in table 3. The demographic data of the both groups were similar and comparable. No statistical differences seen between the groups for patient's age, sex, weight and ASA classification. The level of sedation was assessed using Ramsey Sedation Scale
(RSS) and in the both groups RSS, operating time and recovery time were comparable $(P>0.05)$.

\begin{tabular}{llc}
\multicolumn{2}{c}{ Table 3. Demographic data. } \\
& Group A ( No:50) & Group B (No: 50) \\
Age(years) mean \pm SD & $33.27 \pm 1.32$ & $30.38 \pm 1.28$ \\
Sex (M:F) & $33: 17$ & $35: 15$ \\
ASA I:II & $39: 11$ & $41: 9$ \\
Weight(kg) mean $\pm S D$ & $57.9 \pm 8.7$ & $60.8 \pm 6.5$ \\
Duration of Surgery & $16.19 \pm 7.5$ & $17.26 \pm 5.4$
\end{tabular}

Hemodynamic parameters (pulse rate, NIBP) increased at the time of incision but were within the acceptable level. Respiration rate was decreased and was shallow in many patients. SpO2 was decreased below $90 \%$ in 32 cases and apnea was seen in 12 cases, all treated with positive pressure ventilation with oxygen. Respiratory depression was seen more frequently in the Propofol group than in the Ketofol. In this study 19 patients had shallow and slow respiration and 5 patients had apnea in Propofol group where as 13 patients had shallow and slow respiration and 7 had apnea in Ketofol group. There was no significant change in vital parameters after $5 \mathrm{~min}$ and at the end of the surgery. There was no decrease in SBP and pulse rate seen in any cases.

$\begin{array}{lcc}\text { Table 4. Intraoperative Complications. } & \\ \text { Group A } & \text { Group B } \\ \text { SpO2 }<90 \% & 13 & 19 \\ \text { Apnea } & 7 & 5 \\ \text { Tachycardia }>120 & 3 & 7\end{array}$

The mean induction time required for the Ketofol group was $32.18 \pm 4.17 \mathrm{sec}$ and for propofol group it was $39.34 \pm 5.12 \mathrm{sec}$. Similarly the mean surgical and recovery time also comparable in both groups. The minimum requirement of anesthetic solution in Ketofol group was $5 \mathrm{ml}$ and in Propofol group it was $8 \mathrm{ml}$. The average requirement of sedation was $9.16 \pm 4.32 \mathrm{ml}$ in Ketofol group was and $13.42 \pm 3.24 \mathrm{ml}$ in Propofol group. The requirement of the anesthetic solution in ketofol group was much less than the propofol group and is statistically significant $(P<0.05)$. The average surgical time was 16.19 $\pm 7.5 \mathrm{~min}$ in Ketofol group and was 17.26 $\pm 5.4 \mathrm{~min}$ in Propofol group and was statistically comparable ( $P>0.05)$. No intra operative nausea and vomiting seen in any case of both groups. The AVPU scale was used to assess the recovery status of all patients and all transferred to the post operative room only after the verbal response. The average recovery time was 4.26 $\pm 2.19 \mathrm{~min}$ in Ketofol group and 5.16 $\pm 3.48 \mathrm{~min}$ in Propofol group. 
Table 5. Comparison of anesthesia parameters.

Group A Group B P-Value

$\begin{array}{llll}\text { Mean induction time }(\mathrm{sec}) & 32.18 \pm 4.17 & 39.34 \pm 5.12 & >0.05 \\ \text { Mean surgical time }(\mathrm{min}) & 16.19 \pm 7.5 & 17.26 \pm 5.4 & >0.05 \\ \text { Mean recovery time }(\mathrm{min}) & 4.26 \pm 2.19 & 5.14 \pm 3.48 & >0.05 \\ \text { Study solution }(\mathrm{ml}) & 9.16 \pm 4.32 & 13.42 \pm 3.24 & <0.05 \\ \text { Ramsay sedation scale } & & & \\ \text { at } 5 \text { min } & 5.68 \pm 0.24 & 5.48 \pm 0.36 & >0.05 \\ \text { Verbal rating scale } & 2.28 \pm 0.72 & 3.2 \pm 0.44 & >0.05\end{array}$

All postoperative patients were kept at least for 4 hours in post operative room and then discharged if there were no any adverse events. Post operative pain was assessed with Verbal Rating Scale (VRS) using 0 for no pain, 1 for slight pain, 2 for moderate and 3 for the severe pain and 4 for the severe unbearable pain (Table 2 ).

$\begin{array}{lcc}\begin{array}{l}\text { Table 6. Postoperative Complications. } \\ \text { Group A (Ketofol) }\end{array} & \begin{array}{c}\text { Group B (Propofol) } \\ \text { Postoperative pain (No) }\end{array} & 9 \\ \text { Nausea } & 5 & 2 \\ \text { Vomiting } & 1 & 0 \\ \text { Psychotomimetic effects } & 3 & 0\end{array}$

Intramuscular analgesic solution diclofenac sodium was prescribed when VRS was 3 or more. Out of 100 analyzed patients 23 patients demanded analgesia, 9 from the ketofol group and 14 from propofol group due to severe pain (VRS 3 4) and were treated with IM injection of $75 \mathrm{mg}$ of diclofenac sodium. Rest of the patients had minimal pain or bearable pain.

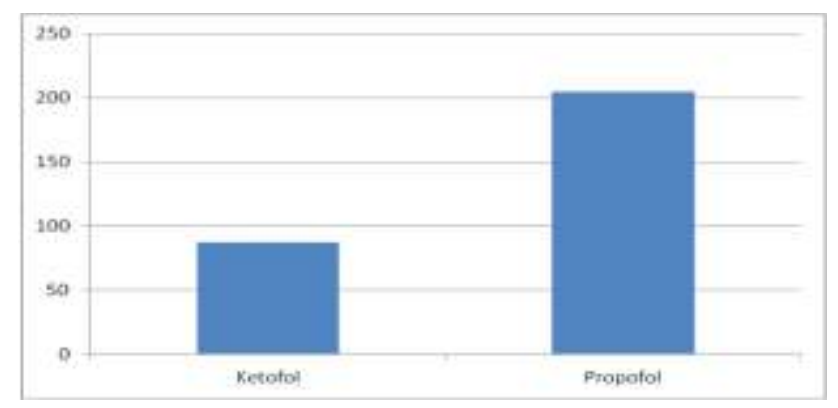

Figure 1: Comparison of cost of study solution

Postoperative nausea vomiting seen in 8 patients where 5 patients developed nausea in ketofol group and 2 in propofol, however vomiting seen only in 1 patient of ketofol group and all treated with $10 \mathrm{mg}$ of intravenous injection of metoclopramide. Ketamine induced psychotomimetic effect seen in 3 patients and were managed by closed observation and no any pharmacological intervention was required

\section{DISCUSSION}

PPropofol is an IV anesthetic agent used for the induction and maintenance of intravenous anesthesia. ${ }^{8}$ The recovery from the propofol induced anesthesia is generally rapid with less frequent side effects than other inducing agents. ${ }^{8}$ It is a short acting lipophillic sedohypnotic agent which causes CNS depression through agonist action on GABAA receptors and it has no analgesic property. ${ }^{8}$ It has very fast onset of action about 15-30 sec with duration of action of 3-10 min. ${ }^{8}$ Propofol has some side effects and are respiratory and cardiac depression, decreased $\mathrm{SpO} 2$, however it has property of rapid induction, deep anesthesia, antiemetic and anti pruritic effect. So it is a popular agent used for induction of anesthesia and for the sedation in minor surgical procedures. It is also used for the maintenance of anesthesia as an infusion or in intermittent small doses. ${ }^{3.8}$

Ketamine is a non barbiturate dissociative anesthetic agent acts primarily as an antagonist of the NMDA receptors. ${ }^{5.9}$ According to WHO $2 \mathrm{mg}$ per $\mathrm{kg}$ of ketamine given intravenously over 60 seconds produces surgical anesthesia within 30 seconds which continues for 5-10 min and resolves completely in 1-2 hours. ${ }^{10,11}$ Analgesic effect of ketamine can be obtained by intravenous administration of $0.2-0.75 \mathrm{mg} / \mathrm{kg}(\mathrm{WHO}){ }^{12}$ Ketamine is a mild respiratory depressant and also has a bronchodilatory effect with maintained pharyngeal and laryngeal reflexes. ${ }^{5,13}$ Ketamine is only available intravenous anesthetic agent having analgesic, sedo-hypnotic and amnestic properties and least economical than any other similar agents. ${ }^{9}$ So ketamine can be successfully used as an ideal anesthetic agent producing analgesia, unconsciousness, amnesia and akinesia. ${ }^{509}$ Being all the benefits, ketamine is four times cheaper than the propofol so its cost effectiveness is also responsive for its increased use in operating room, emergency and intensive care department and field surgery. ${ }^{5}$

The combination of propofol and ketamine produces more stable hemodynamic condition than ketamine or propofol used individually. Ketamine with propofol for the sedation is gaining popularity due to the increased analgesic effect of ketamine and reduction of the side effects of propofol. ${ }^{6}$

Ketamine and propofol in combination in separate syringes has been used successfully for the analgesia for minor procedures in adults and children by several authors. ${ }^{3}$ This combination has the property of the opposite respiratory and cardiovascular effects of each drugs. ${ }^{3}$ Friedbourg investigated 1264 patients for surgical procedures with ketamine and propofol and concluded that the combination is safe and effective. ${ }^{3}$ This combination also reduces the dose of expensive drug propofol to achieve the desired effect. The combination has the less adverse effects than the either drug alone due to their complementary effects of lowering the dose of both drugs. ${ }^{4}$ Ketamine is a strong analgesic which effectively reduces the injection pain of propofol by attenuating the afferent pain pathways. ${ }^{14}$

Ketofol is mixture of ketamine and propofol in a same syringe in various concentration used effectively as an inducing agent in operating room and in ambulatory setting. ${ }^{15}$ It is also believed that these two agents have synergistic effect for the sedation and at the same time counteract the side effect of each other. ${ }^{4}$ In a study by Khajabi et al the ketofol has shown to have an effective sedative property and is better than other combination of propofol with fentany and pethidine. ${ }^{16}$ In addition, the ketofol combination has low incidence of psychomimetic reaction of ketamine seen in the postoperative room. ${ }^{10,11}$ These two molecules can be successfully mixed in a single syringe in 1:1 proportion without any chemical changes 
which was investigated by several authors and found that such proportions is safe and efficient for analgesia and sedation. ${ }^{4}$ It is also reported that ketamine and propofol are physically compatible and chemically stable and can be mixed in a single syringe and the mixture can be stored too. ${ }^{4}$

Triss LA investigated about the compatibility of propofol with other various agents and reported that ketamine and propofol are physically compatible for $1 \mathrm{hr}$ at $23^{\circ} \mathrm{C}^{17}$ In another study done by RF Donnelly the combination of ketamine and propofol in either 50:50 or 30:70 proportion in a plastic syringe were physically and chemically stable for at least $3 \mathrm{hr}$ when stored at room temperature with exposure of light. ${ }^{18}$ In this study ketofol mixture was prepared freshly just before the induction and the remaining drug stored in refrigerator and used within $3 \mathrm{hr}$.

Ketamine also has antibacterial and antifungal activity against some organisms in propofol, which is known to be a growth promoting solution for microorganisms. So the combination of both solutions in a single syringe may reduce the risk of infection caused by accidental contamination of the mixture. ${ }^{1}$

Badrinath et al used different concentration of ketaminepropofol combination for sedation for female patients undergoing breast biopsy and did not encounter any severe respiratory complications. ${ }^{6 / 19}$ In this study minor respiratory complications seen in the both groups and were transient apnea and decrease in $\mathrm{SpO} 2$ below $90 \%$ and all treated with positive pressure ventilation with $\mathrm{O} 2$.

The minimum dose of study solution required in Ketofol group was $5 \mathrm{ml}$ and in Propofol group it was $8 \mathrm{ml}$ and the average requirement of Ketofol was $9.16 \pm 4.32 \mathrm{ml}$ and in

\section{REFERENCES}

1. Begec Z, Yucel A, Yakupoqullary Y, Ergodan MA. The antimicrobial effects of ketamine combined with propofol: An in vitro study. Braz J anesthesiol. 2013 Nov-Dec;63(6):461-5

2. Simad MA, Islam MS, Ahmed M, Maruf AA. Evaluation $f$ ketofol as total intravenous anesthetic for burn dressing in adult patients. JAFMC Bangladesh. Vol 8, No 1: June 2012:20-24

3. Elaine VW, Gary A. A prospective evaluation of "Ketofol" for procedural sedation and analgesia in the emergency department. Annals of emergency medicine. Vol 49, No. 1; Jan 2007: 23-30.

4. Hoda Shokri. Ketamine-propofol sedation versus propofolpethidine sedation for minor plastic surgery procedures. Ains Shams Journal of Anesthesiology. Vol 9, Issue 2; 2016: 245-249.

5. Kurdi MS, Theerth KA, Dewa RS. Ketamine: current application in anesthesia, pain and critical care. Anesth Essays and Res. 2014 SepDec; 8(3): 283-290.

6. Isik y, Kurdoglu Z, Goktas U,Kati I, Sozen D. Comparison of propofol and ketofol in minor gynecological interventions. J Clin Exp Invest. Vol 6, No 3, Sep 2015: 244-249.

7. Bech RD, Lauritsen J, Ovesen $\mathrm{O}$, Overgaard $\mathrm{S}$. The verbal rating scale is reliable for assessment of postoperative pain in hip fracture patients. Pain Research and Treatment. Vol 2015, Article ID 676212.

8. Kotani $\mathrm{Y}$, Shimazawa M, Yoshimura S, Iwama T,Hara H. The experimental and clinical pharmacology of propofol, an anesthetic agent with neuroprotective proporties. CNS Neurosciences and Therapeutics. 14(2008) 95-106.

9. White PF, Way WL, Trevor AJ. Ketamine, its pharmacology and therapeutic uses. Anesthesiology 1982;56:119-136.

10. Creesey DM, Claydon P, Bhaskaran NC, Reilly CS. Effect of midazolam pretreatment on induction dose requirements of propofol in combination with fentanyl in younger and older adults. Anaesthesia 2001; 56:108-113.
Propofol group $13.42 \pm 3.24 \mathrm{ml}$. This study was also carried out to find the cost effectiveness of the mixture of ketamine and propofol too. The average requirement of study solution in Group A was $9.16 \mathrm{ml}$ means $45.8 \mathrm{mg}$ of propofol and $45.8 \mathrm{mg}$ of ketamine. The price of $10 \mathrm{mg}$ of propofol is 16 rupees and $10 \mathrm{mg}$ of ketamine is 4 rupees, so the price of $9.16 \mathrm{ml}$ of study solution of group A is 91.6 rupees, however in the propofol group the cost of the $13.42 \mathrm{ml}(134.2 \mathrm{mg})$ of the solution is 214.72 rupees. In this study ketofol group provided similar anesthesia for minor surgical procedures with more than two times cheaper than the propofol group and is statistically significant $(P<0.05)$.

All patients were comfortable in the postoperative room and discharged after four hours of surgery and no any patient was admitted due to the postoperative complications. The only seen postoperative complications were pain, hallucinations, nausea and vomiting and all treated successfully and discharged at the same day.

\section{CONCLUSION}

The combination of ketamine and propofol has several advantages over the propofol alone for the anesthesia in minor surgical procedures. The combination is cost effective, better sedation and analgesia, hemodynamic stability and quick recovery seen in the operating room. The combination has less adverse effects than the either drug alone due to their complementary effects of lowering the dose of both drugs.

\section{CONFLICT OF INTEREST}

None.

11. Strayer RJ, Nelson LS. Adverse events associated with ketamine for procedural sedation in adults. Am J Emerg Med 2008; 26:9851028.

12. Ketamine, Update Review Report. World Health Organization. Thirty-sixth Meeting. Geneva, 16-20 June 2014

13. Reich D, Silvay G. Ketamine: An update on the first twenty-five years of clinical experience. Canadian Journal of Anesthesia 1989; 36:2; pp 186-197.

14. Samad MA, Islam MS, Ahmed M, Maruf AA. Evaluation of ketofol as total intravenous anesthetic for burn dressing in adult patient. JAFMC Bangladesh. Vol 8, No1(June) 2012: 20-24

15. Montero RF, Clark LD, Tolan MM et al. The effects of small dose ketamine on propofol sedation: respiration, postoperative mood, perception, cognition and pain. Anesthesia Analgesia. 2001;92:1465-1469.

16. Khajavi M, Emami A, Moharari RS. Conscious sedationand analgesia in colonoscopy: ketamine propofol combination has superior patient satisfaction versus fentanyl propofol. Anesth Pain Med. 2013 Summer; 3(1); 208-213.

17. Trissel LA, Gilbert DL, Martinez JF. Compatibility of propofol injectable emulsion with selected drugs during simulated Y-site administration. American Journal of Health-System pharmacy. June 1997, 54(11) 1287-1292.

18. Donnelly RF, Willman E, Andolfatto G. Stability of KetaminePropofol Mixtures for Procedural Sedation and Analgesia in the Emergency Department. Can J Hosp Pharm 2008;61(6):426-430.

19. Badrinath $S$, Avramov MN, Shadrick M, Ivankovich AD. The use of a ketamine -propofol combination during monitored anesthesia care. Anesthesia and Analgesia: April 2000; Vol 90(4):858-862. 